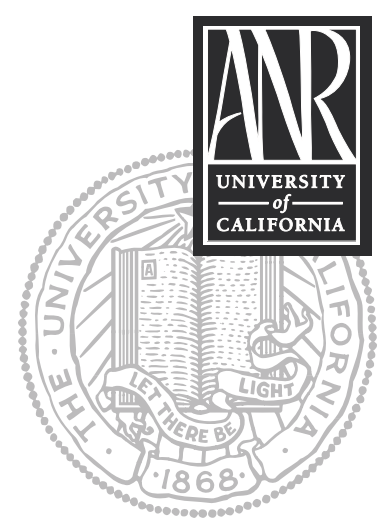

UNIVERSITY OF CALIFORNIA

Division of Agriculture and Natural Resources http://anrcatalog.ucdavis.edu

\title{
Growing Seed Sprouts at Home
}

TREVOR V. SUSLOW, Department of Vegetable Crops, UC Davis; and LINDA J. HARRIS, Department of Food Science and Technology, UC Davis.

Since 1995, raw sprouts have emerged as a significant source of foodborne illness in the United States. These illnesses have involved the pathogenic bacteria Salmonella and E. coli O157:H7. Alfalfa, clover, and mung bean sprouts have been involved most frequently, but all raw sprouts may pose a risk.

For most outbreaks, the source of contamination appears to have been the seed. Even if the seed is contaminated, pathogen levels are typically very low, so contamination can easily be missed depending on the nature of the seed-testing program. The best conditions for sprouting are also ideal for multiplication of pathogenic bacteria if they happen to be present on the seed. Even if the seed are only lightly contaminated, Salmonella and E. coli O157:H7 levels can increase to millions of cells per serving during the sprouting process.

Because illnesses from these organisms can range from mild to extremely unpleasant and even to very severe in susceptible persons, the U.S. Food and Drug Administration and the California Department of Health Services have issued warnings to consumers:

Food and Drug Administration is advising all persons to be aware of the risks associated with eating raw sprouts (e.g., alfalfa, clover, radish). Outbreaks have included persons of both genders and all age categories. Those persons who wish to reduce the risk of foodborne illness from sprouts are advised not to eat raw sprouts.

This advice is particularly important for children, the elderly, and persons with weakened immune systems, all of whom are at high risk of developing serious illness due to foodborne disease. People in high-risk categories should not eat raw sprouts. Cooked sprouts can be eaten if heated to steaming hot or above $165^{\circ} \mathrm{F}\left(74^{\circ} \mathrm{C}\right)$. This type of treatment is most applicable to mung bean sprouts.

\section{HOW DOES THE SPROUT INDUSTRY ADDRESS FOOD SAFETY?}

The sprout industry has been working in cooperation with industry groups, government, and university researchers to enhance the safety of its products. These efforts have focused on a combination of the following:

- improved seed management strategies, including use of seed that has been grown, harvested, stored, and transported under conditions that minimize the potential for contamination with pathogenic organisms

- seed sourced as described above, coupled with seed testing and certification programs

- a sprouting process that follows appropriate sanitary practices, including sanitary maintenance of facilities and equipment that will protect the product from contamination

- treatment of seed prior to sprouting with high concentrations of calcium hypochlorite or other disinfectants with equivalent activity

- testing of irrigation water from each production lot for Salmonella and E. coli O157:H7 
Although these steps probably will significantly reduce the risk of foodborne illness associated with commercially grown sprouts, we have limited historical evidence to back this up. Because of this, the FDA and the California Department of Health Services still recommend that high-risk consumers avoid eating any type of raw sprouts.

\section{GROWING SEED SPROUTS AT HOME}

Sprouts grown in the home also present a risk if eaten raw, since most outbreaks have been attributed to contaminated seed. If pathogenic bacteria are present in or on the seed, they can multiply to high levels during sprouting even under clean conditions. Should previously pathogen-free seed or sprouting implements (domes, trays, flats, etc.) become contaminated in the home, the same concerns would apply as under commercial growing conditions. The sprout industry currently applies a 2 percent calcium hypochlorite solution to the seed for about 10 minutes prior to washing with clean water and sprouting. Sodium hypochlorite (household bleach), the most common source of chlorine in the home, is not labeled for this purpose, however, and neither is granular calcium hypochlorite (used for treating swimming pools). Use of chlorine at these levels is not recommended for treating seeds in the home.

The following steps are suggested for those who want to produce sprouts at home:

1. Buy certified (pathogen-free) seed* AND

2. Treat the seed by heating on the stovetop for five minutes in a solution of $3 \%$ hydrogen peroxide (available at most drug stores) preheated to $140^{\circ} \mathrm{F}\left(60^{\circ} \mathrm{C}\right)$. Use a clean, accurate cooking thermometer (preferably digital) to reach and maintain this temperature during treatment. Typically, the small seed volumes used for home sprouting can easily be contained in a small mesh strainer and immersed directly into the heated peroxide solution. Swirl the strainer at oneminute intervals to achieve uniform treatment. For larger volumes, stir the seed occasionally during the heating process to ensure uniform temperature during treatment. Always discard the peroxide solution after each seed batch as its effectiveness will rapidly decline.

3. Rinse the seed in running tap water for 1 minute. In addition, we recommend that you place the rinsed seed in a container with enough tap water to cover the seed plus one inch. Then carefully skim off all floating seed, seed coat fragments, and other debris and dispose of them. Although skimming can be a tedious process, research has tied most contamination to these materials.

4. Sprout the seed in clean, sanitized containers, well away from areas of food preparation, pets, and high household traffic.

To sanitize sprouting containers:

Follow the directions on the bleach container (use plain, not scented laundry bleach) for sanitizing kitchen surfaces. Use $3 / 4$ cup of bleach per gallon of water ( 3 tablespoons per quart) and soak the container for at least 5 minutes. Then rinse with clean water.

5. Follow precautions for consumption as below.

If sprouts are made in the home and eaten raw, young children, elderly persons, or persons with weakened immune systems should NOT eat them.

* Current sources include Burpee Seed Co. (http://www.burpee.com) and Sprout People (http://www.sproutpeople.com). If you are buying seed to sprout at home, make sure to specifically request pathogen-free certification, as the seed is not marketed as such. Certified organic sprout seed is available from several sources, but the term "organic" does not necessarily mean that the seed is pathogen-free or that it has been tested for pathogens. At the same time, this does not suggest that organically grown seed poses any elevated risk of illness. 


\section{ADDITIONAL REFERENCES}

\section{Web sites}

Information from the U.S. Food and Drug Administration for commercial sprouters: http://www.foodsafety.gov/ dms/fs-toc.html\#prod

Information from the U.S. Food and Drug Administration for consumers: http://www.cfsan.fda.gov/ lrd/hhssprts.html

International Sprout Grower's Association: http://www.isga-sprouts.org/

Sprout Net Archives (at International Specialty Supply): http://www.sproutnet.com/

\section{Publications}

Beuchat, L. R. 1997. Comparison of chemical treatments to kill Salmonella on alfalfa seeds destined for sprout production. International Journal of Food Microbiology 34:329-333.

Schrader, W. L. 2002. Sprout Production in California. Oakland: University of California, Agriculture and Natural Resources Publication 8060.

http://anrcatalog.ucdavis.edu

Suslow, T., and M. Cantwell. Recommendations for Maintaining

Postharvest Quality: Seed Sprouts:

http://postharvest.ucdavis.edu/Produce/ProduceFacts/Veg/seedsprouts.shtml)

\section{FOR MORE INFORMATION}

You'll find detailed information on many aspects of food safety and nutrition in these titles and in other publications, slide sets, CD-ROMs, and videos from UC ANR:

Key Points of Control and Management for Microbial Food Safety: Edible Landscape Plants and Home Garden Produce, Publication 8101

Tomatoes: Safe Methods to Store, Preserve, and Enjoy, Publication 8116

Home Pickling of Olives, Publication 2756

To download these products, visit our online catalog at http://anrcatalog.ucdavis.edu. You can also place orders by mail, phone, or FAX, or request a printed catalog of publications, slide sets, CD-ROMs, and videos from

University of California

Agriculture and Natural Resources

Communication Services

6701 San Pablo Avenue, 2nd Floor

Oakland, California 94608-1239

Telephone: (800) 994-8849 or (510) 642-2431, FAX: (510) 643-5470

E-mail inquiries: danrcs@ucdavis.edu

An electronic version of this publication is available on the ANR Communication Services Web site at http://anrcatalog.ucdavis.edu.

Publication 8151

(C) 2004 by the Regents of the University of California, Division of Agriculture and Natural Resources. All rights reserved. 
The University of California prohibits discrimination or harassment of any person on the basis of race, color, national origin, religion, sex, gender identity, pregnancy (including childbirth, and medical conditions related to pregnancy or childbirth), physical or mental disability, medical condition (cancer-related or genetic characteristics), ancestry, marital status, age, sexual orientation, citizenship, or status as a covered veteran (covered veterans are special disabled veterans, recently separated veterans, Vietnam era veterans, or any other veterans who served on active duty during a war or in a campaign or expedition for which a campaign badge has been authorized) in any of its programs or activities.

University policy is intended to be consistent with the provisions of applicable State and Federal laws.

Inquiries regarding the University's nondiscrimination policies may be directed to the Affirmative Action/Staff Personnel Services Director, University of California, Agriculture and Natural Resources, 300 Lakeside Drive, $6^{\text {th }}$ Floor, Oakland, CA 94612-3550, (510) 987-0096. For information about obtaining this publication, call (800) 994-8849. For downloading information, call (530) 754-5112.

\section{WARNING ON THE USE OF CHEMICALS}

Pesticides are poisonous. Always read and carefully follow all precautions and safety recommendations given on the container label. Store all chemicals in their original labeled containers in a locked cabinet or shed, away from foods or feeds, and out of the reach of children, unauthorized persons, pets, and livestock.

Confine pesticides to the property being treated. Avoid drift onto neighboring properties or gardens containing fruits and/or vegetables ready to be picked.

Dispose of empty containers carefully. Follow label instructions for disposal. Never reuse the containers. Make sure empty containers are not accessible to children or animals. Never dispose of containers where they may contaminate water supplies or natural waterways. Do not pour down sink or toilet. Consult your county agricultural commissioner for correct ways of disposing of excess pesticides. Never burn pesticide containers.

PHYTOTOXICITY: Certain chemicals may cause plant injury if used at the wrong stage of plant development or when temperatures are too high. Injury may also result from excessive amounts or the wrong formulation or from mixing incompatible materials. Inert ingredients, such as wetters, spreaders, emulsifiers, diluents, and solvents, can cause plant injury. Since formulations are often changed by manufacturers, it is possible that plant injury may occur, even though no injury was noted in previous seasons.

This publication has been anonymously peer reviewed for technical accuracy by University of California scientists and other qualified professionals. The review process was managed by the ANR Associate Editor for Food and Nutrition. 